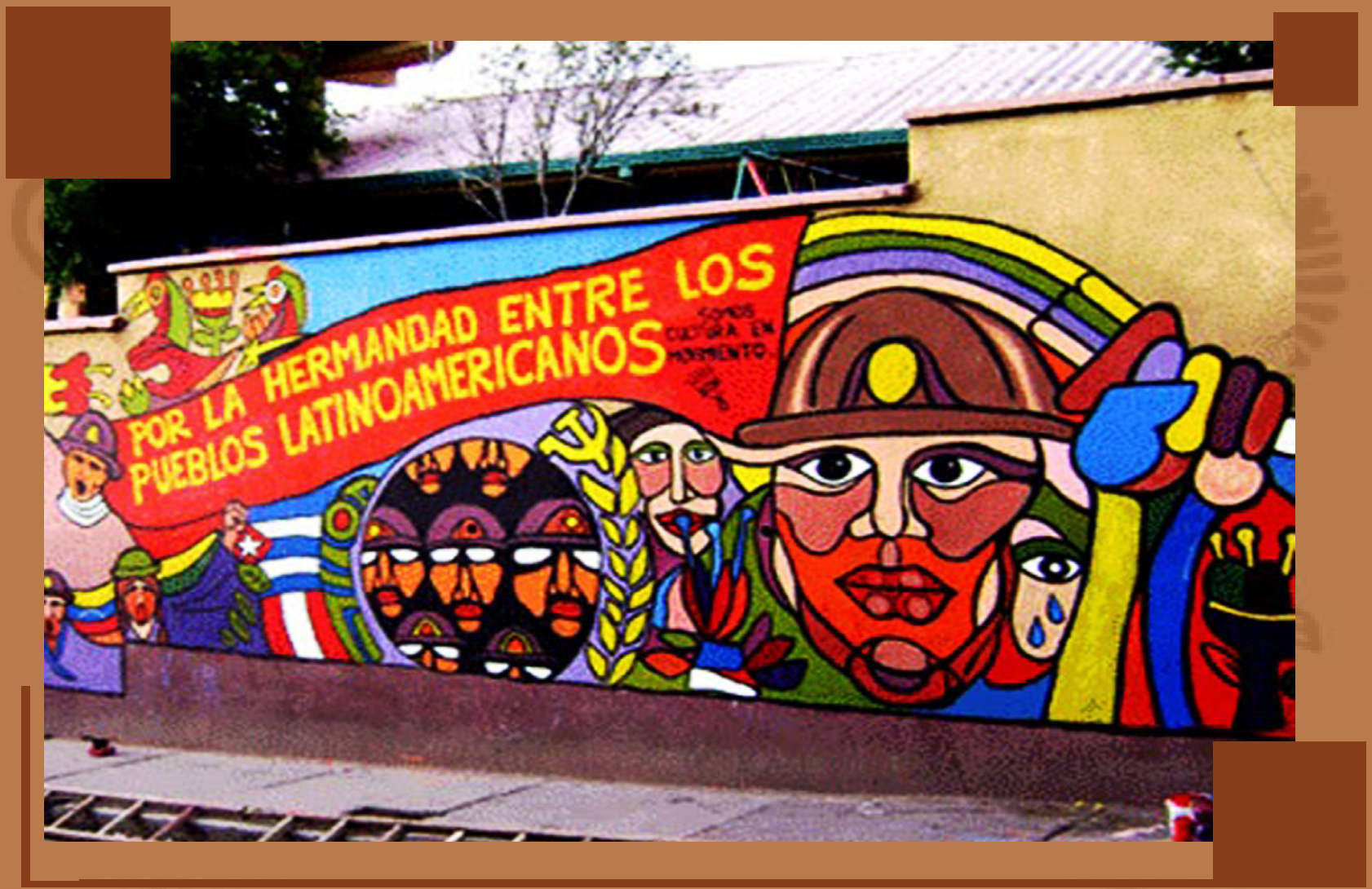

Luchas y desafíos de los movimientos sociales en centro América en el último quinquenio

Realidades Urbanas y Rurales 


\section{Luchas y desafíos de los movimientos sociales en centro América en el último quinquenio}

\section{Struggles and challenges of social movements in Central America in the last five years}

Zulma Larín de Vides

Coordinadora Red de Ambientalistas Comunitarios de El Salvador-RACDES

ID Orcid: https://orcid.org/0000-0002-3335-9752

larin.zulma@gmail.com
Recibido: 20-10-2019

Aceptado: 17-11-2019

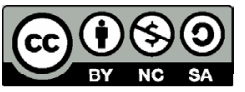

Copyright $\odot 2020$ UNAN-Managua Todos los Derechos Reservados.

\section{Resumen}

Este ensayo pretende dar algunas luces del como los movimientos sociales son importantes organizaciones que se han formado en la historia de la humanidad para buscar alternativas y soluciones a las condiciones de vida que hacen que una sociedad sea más culta, prospera y donde el ejercicio del goce pleno de los Derechos Humanos desde la inclusión, igualdad y equidad deben ser el motor de trabajo de todos los estados. También este ensayo pretende dar una idea general del como los movimientos sociales han estado realizando su trabajo en los últimos 5 años en Centro América; Así como algunos desafíos y retos que hay como movimientos sociales en la región.

Palabras claves: Movimientos sociales, Luchas históricas, Extractivismo, Capitalismo

\section{Abstract}

This essay aims to give some light on how social movements are important organizations that have formed in the history of humanity to seek alternatives and solutions to living conditions that make a society more cultured, thrives and where the exercise of enjoyment Full of Human Rights since inclusion, equality and equity must be the work engine of all states. This essay also aims to give a general idea of how social movements have been doing their work in the last 5 years in Central America; As well as some challenges and challenges that exist as social movements in the region.

Keywords: Social movements, Historical struggles, Extractivism, Capitalism

Fuente de la Portada: Nodal, noticias de America Latina y el Caribe. 
Un movimiento social es un grupo no formal de individuos $u$ organizaciones dedicadas a cuestiones socio-políticas que tiene como finalidad el cambio social.

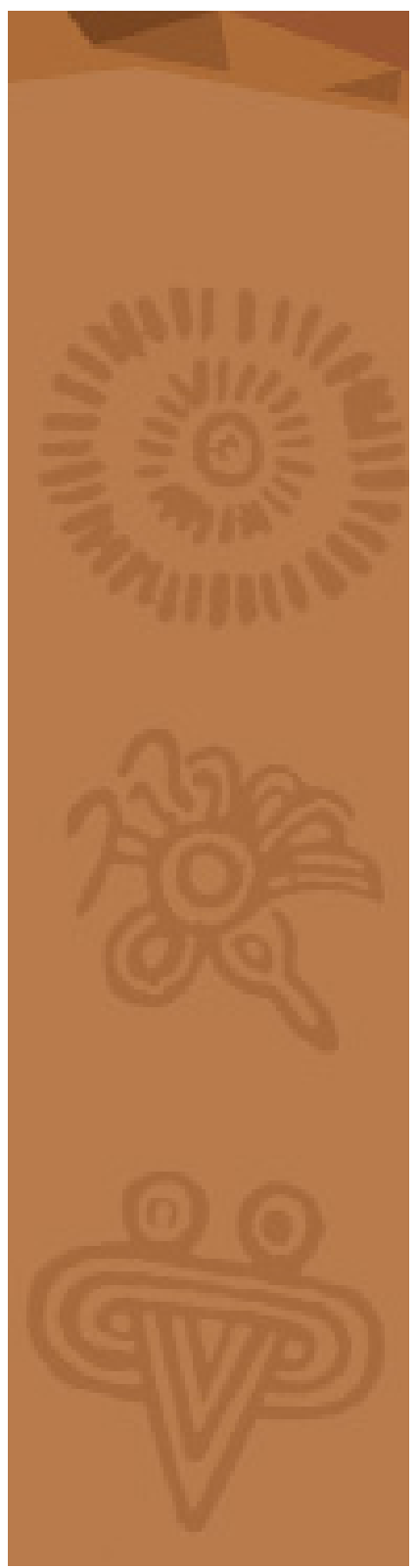

\section{Introducción}

La importancia que ejercen los movimientos sociales dentro del Estado y sus relaciones de causal y efectos como fenómenos sociales de gran complejidad por lo que adquiere la necesidad de encontrar puntos de equilibrio dentro de un mundo globalizado y competitivo, quedan más expuestas las prioridades y exigencias del ser humano dentro de su entorno, su desarrollo y desenvolvimiento cotidiano en búsqueda de satisfacer sus necesidades y a la vez necesidades de un conglomerado social, dando a conocer y entender que el surgimiento y el fortalecimiento de los movimientos sociales tienen que ser entendidos como consecuencias de un cambio de la base funcional a una base territorial y cultural de la acción colectiva y la dinámica social asociada dentro de un determinado contexto histórico, social y cultural, además de la reflexión sistemática o sociológica de las características de estos actores políticos, hoy, claves para la estabilidad y la transformación social, en búsqueda de las características internas, las bases socio-territoriales, las tácticas de resistencia, la lucha, y las alianzas forjadas de los movimientos sociales orientadas en el vivir bien de todos los miembros de la sociedad.

\section{¿Que son los movimientos sociales?}

Un movimiento social es un grupo no formal de individuos u organizaciones dedicadas a cuestiones socio-políticas que tiene como finalidad el cambio social. Cuando empezó a utilizarse a principios del siglo XIX, el concepto de movimiento social estaba ligado a un tipo de cambio social particular (revolucionario) y a un fin específico (la instauración de un régimen socialista o comunista), así como a una identidad en concreto (identidad de clase) y a un grupo social en particular la clase obrera (Alberto, 1991).

Así el mismo término engloba movimientos que se sitúan en muy diferentes contextos, en objetivos que se encuentran en esferas tan distintas como la cultural, social, política, económica o personal, y cuya composición incluye a clases, sectores, como obreros, campesinos, mujeres, estudiantes, vecinos y grupos étnicos.

En su conceptualización más general, los movimientos sociales son definidos como "una forma de acción colectiva no efímera, en la cual un grupo organizado recurre a acciones extra institucionales para cambiar el estado de las cosas que dañan a la sociedad en su conjunto.

\section{Contexto histórico de los movimientos sociales}

Los movimientos sociales como estructuras de cambio social surgieron históricamente como consecuencia de distintas crisis sociales y presentaron distintas orientaciones ideológicas: tanto revolucionarias como reaccionarias, y todos los estadios intermedios hasta los marginados, a veces identificados con un campo político más o menos concreto, y en otras ocasiones de forma interclasista y multipartidista. 
América Latina viene experimentando un cambio de época. Diversos procesos sociales y políticos han ido configurando nuevos escenarios

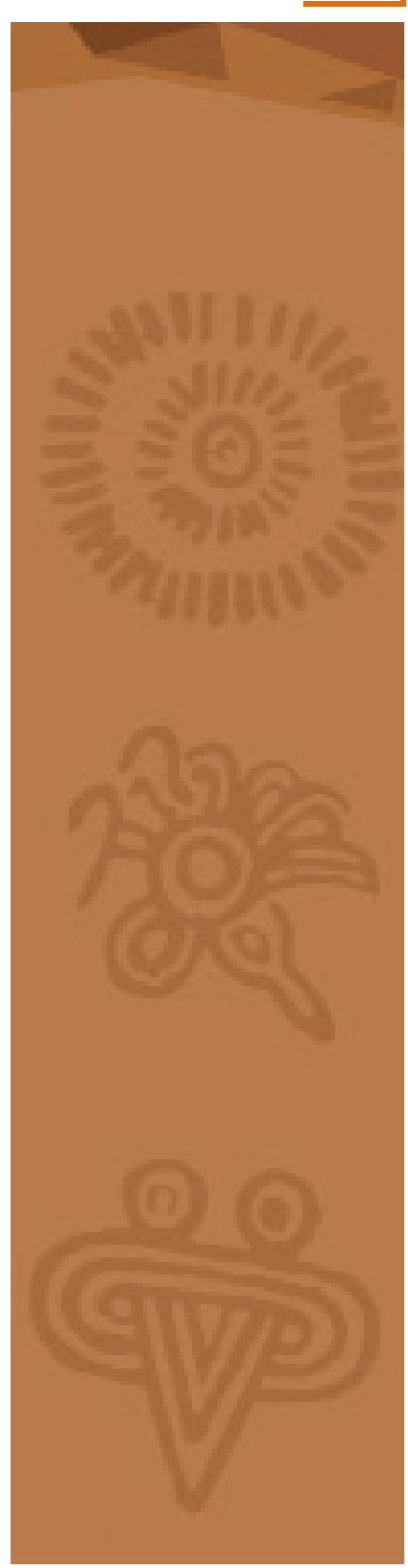

Algunos ejemplos de estos movimientos son el movimiento feminista, el movimiento ecologista, el movimiento obrero, el movimiento pacifista o antimilitarista, o, más reciente en su surgimiento, el movimiento okupa y el movimiento antiglobalización

El término fue introducido al vocabulario académico por Lorenz Von Stein en 1846 ("Historia de los Movimientos Sociales Franceses desde 1789 hasta el Presente (1850). Stein entiende un Movimiento Social como, básicamente, una aspiración de sectores sociales (clases) de lograr influencia sobre el Estado, debido a las desigualdades en la economía. Así, por ejemplo, la aspiración del proletariado a lograr representación en los sistemas de gobierno.

\section{Los movimientos sociales en América Latina: Un balance histórico}

Los cambios recientes en América Latina se expresan no sólo en movimientos sociales y populares cada vez más originales y activos sino también en un nuevo escenario político marcado por la existencia de gobiernos de centro-izquierda bajo una fuerte presión de la sociedad civil y de movimientos de masa. Esta nueva coyuntura está redefiniendo el escenario político en la región y está abriendo un proceso histórico que presenta elementos nuevos que van a influir profundamente en la dinámica económica, política, cultural y social inmediata, pero también en el mediano y largo plazo.

Una comprensión más objetiva de esta nueva coyuntura en la región exige un análisis profundamente histórico, capaz de hacer un balance de la lucha secular de las fuerzas progresistas que ha generado una acumulación de experiencias extremamente rica. Lucha secular que tiene que ver con elementos claves de nuestra identidad como latinoamericanos, como naciones capaces de conducirse a sí mismas y que tienen una presencia cultural basada en una fuerza civilizatoria propia.

América Latina viene experimentando un cambio de época. Diversos procesos sociales y políticos han ido configurando nuevos escenarios : la crisis del consenso neoliberal, la relegitimación de los discursos críticos, la potenciación de diferentes movimientos sociales, los gobiernos autodenominados "progresistas" y de centroizquierda, son algunas notas distintivas de un período de transición.

Esos nuevos escenarios desembocaron en una modificación de las relaciones de clase, lo cual repercutió, enormemente en el modo en cómo cada grupo social se auto representa, se piensa y figura su destino social dentro de la sociedad.

En ese contexto de gran asimetría surgen y se desarrollan las luchas de los movimientos sociales en los ' 90 . Aunque esos movimientos fueron más que una respuesta defensiva, los movimientos sociales latinoamericanos han venido desarrollando una dimensión más proactiva, que da posibilidades a pensar nuevas alternativas emancipadoras a partir de la defensa y promoción de la vida y la diversidad. 
Treinta años de experiencia neoliberal, comandadas a nivel internacional por el FMl y el Banco Mundial, sumergieron nuestros países en graves problemas económicos que llevaron los movimientos sociales de la región a la defensiva

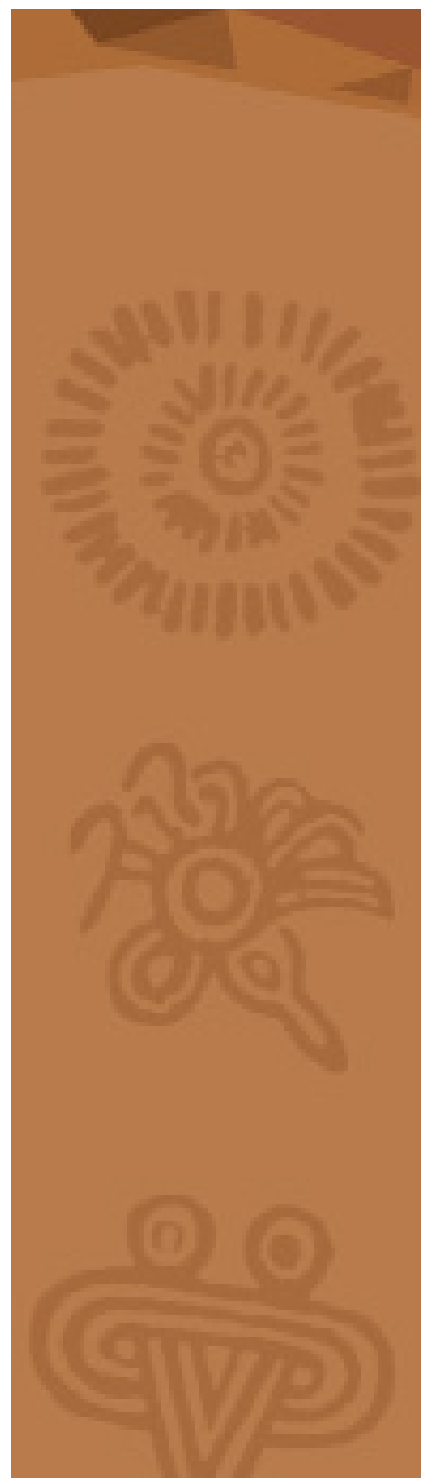

\section{Las luchas sociales en centro América}

Las luchas en Guatemala, El Salvador, Honduras y Nicaragua -y a las respectivas cronologías que aquí se publican-, se desenvuelven en un momento histórico caracterizado por ciertos rasgos comunes como los siguientes: a. situaciones de posguerra, con transiciones hacia la democracia signadas por tensiones entre los proyectos democratizadores y los proclives a una restauración autoritaria; b. la privatización y firma de tratados de libre comercio intra y extrarregionales; c. el desempleo y la informalización del trabajo; d. el éxodo continuo de la población rural y urbana hacia los Estados Unidos; e. la dolarización de las economías, principalmente de El Salvador y Guatemala (las economías de Honduras y Nicaragua caminan más lentamente en esa dirección);f. la subordinación local respecto a las políticas centralistas del Estado; g. el incremento incontrolado del crimen organizado y de la delincuencia; y el abandono y vulnerabilidad de los sectores más pobres frente a los desastres socio naturales (terremotos, sequías y huracanes).

Después de décadas de rebelión armada contra regímenes militares, y del logro de acuerdos negociados para terminar con la guerra (El Salvador en 1992 y Guatemala en 1996), los movimientos sociales, que fueron actores destacados para alcanzar la paz e iniciar la democratización, tienen ahora que innovar sus formas organizativas y de lucha para responder a situaciones inéditas. Los procesos de reconstitución organizativa, no obstante, son todavía precarios. Suponen, en gran medida, una acumulación de nuevos conocimientos, que permitan captar los profundos cambios económicos y culturales que se viven, y que escapan a los parámetros tradicionales del análisis sociopolítico.

\section{Marcadas luchas en el último quinquenio de los movimientos sociales en Centro América.}

Treinta años de experiencia neoliberal, comandadas a nivel internacional por el FMI y el Banco Mundial, sumergieron nuestros países en graves problemas económicos que llevaron los movimientos sociales de la región a la defensiva. El desempleo, la inflación, la dramática caída de los niveles salariales y de calidad de vida, la falta de inversiones en el sector productivo, en infraestructura, o desarrollo social forman un conjunto de fenómenos que va destruyendo el tejido social, que va desestructurando las lealtades institucionales, rompiendo los lazos sociales, abriendo camino a la violencia, migraciones, las drogas y la criminalidad en sus diversas formas de expresión. Los feminicidios se han incrementado en toda la región producto de las políticas neoliberales que se implementan en los países; Aunque no en todos se han aplicado por el igual, el país con mayor desastre es el hermano pueblo de Honduras, le sigue Guatemala, El Salvador, Costa Rica, Panamá y por ultimo Nicaragua en el sentido que Nicaragua aún sigue protegiendo su economía local muy a pesar de las fuertes presiones que ejercen los mismos mecanismos comerciales firmados por todos los gobiernos centroamericanos. 
El capitalismo globalizado tiene sus instituciones: la OMC, el Banco Mundial, el FMI, los bancos regionales y también sus aparatos ideológicos

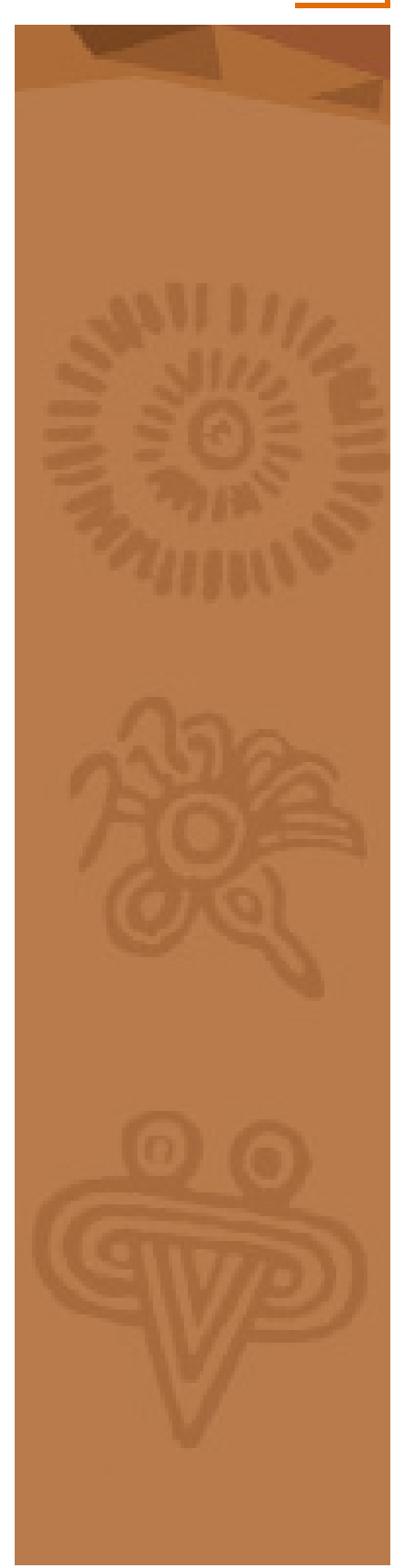

Los proyectos extractivistas son las que más están aprovechando las empresas transnacionales para desarrollar su agenda neoliberal, quitar los aranceles a las importaciones, quitar subsidios a las necesidades básicas, como el gas, alimentos entre otros, privatizaciones de los bienes estratégicos y descapitalizar el estado. La integración de los Pueblos es una necesidad urgente para enfrentar juntos estos procesos de endeudamiento, pérdida de soberanía nacional, violentación de los Derechos Humanos y retrocesos de las democracias alcanzadas producto de tantas luchas y sacrificio de los pobres. No queda otro camino que encontrarnos Los Pueblos y repensar las luchas desde abajo, hacia la izquierda y con los pobres, pero organizadamente ya que si no lo hacemos estaremos condenando a otras generaciones a seguir viviendo en la miseria.

\section{Retos y desafíos de los movimientos sociales}

El capitalismo globalizado tiene sus instituciones: la OMC, el Banco Mundial, el FMI, los bancos regionales y también sus aparatos ideológicos: medios de comunicación social, cada vez más concentrados en pocas manos. Finalmente, goza del poder de un imperio que controla hasta las mínimas expresiones de pensamiento y acción de los pueblos. Para los futuros retos pues es necesario repensar nuestros métodos de trabajo, nuestras visiones ideológicas e integrarlas en las expresiones más plurales y diversas para poder pensar en una democracia más reflexiva, una democracia más participativa e incluyente, una democracia económica sustentada en la economía social y solidaria, una democracia ambiental fundamentada en la sustentabilidad de los elementos naturales; Así como también una democracia cultural expresada en un sentido de la interculturalidad. Las nuevas tecnologías extienden la base material de su reproducción: la informática y la comunicación, que le dan una dimensión realmente global y que debemos de luchar también porque las tecnologías estén educando al pueblo.

\section{Conclusiones}

El nuevo sujeto histórico a construir será popular y plural, es decir constituido por una multiplicidad de actores. Varios pasos son necesarios para producir el nuevo sujeto histórico. La primera condición es de elaborar una conciencia colectiva basada sobre un análisis de la realidad y sobre una ética. En cuanto al análisis se trata de utilizar instrumentos capaces de estudiar los mecanismos de funcionamiento de la sociedad y de entender sus lógicas, con criterios que permitan distinguir efectos y causas, discursos y prácticas. No se trata de cualquier tipo de análisis, sino del aparato teórico crítico lo más adecuado para responder al grito de los de abajo. Exige un rigor metodológico alto y una apertura a todas las hipótesis útiles para este fin. La opción en favor de los oprimidos es un paso pre científico e ideológico, que va a guiar la elección del tipo de análisis, sin embargo este último pertenece al orden científico sin concesión posible. Es un saber nuevo que ayudará a crear la conciencia colectiva.

Los movimientos sociales son cada vez más afectados por las fuerzas sociales emergentes y también se conjugan con la diversidad de pensamientos, acciones identidad propias como expresiones sociales organizadas. Es el caso de los movimientos Feministas, Pueblos Originarios, Afro descendientes, los grupos de defensa del ambiente y otros, que imponen nuevos temas a la agenda de las lu- 
chas sociales. Su punto de partida asume formas diversas de expresión por garantizar derechos y deberes en la incipiente democracia que vive la región.

Con el tiempo, estas reivindicaciones pasan a integrar todo un proyecto cultural que exige el rompimiento con la estructura económico social que generó el machismo, el racismo, el autoritarismo. Los movimientos sociales empiezan así a romper con toda la ideología de la modernidad como forma superior y como única expresión de la civilización. Este enfoque ha dado una fuerza muy especial a los movimientos sociales al presentarlos como fundamento de un nuevo proceso de civilización pluralista, realmente planetario, post-racista, post-colonial y quizás post-moderno.

\section{Bibliografía}

- $\quad$ AMERICA LATINA, UN NUEVO LIDERAZGO PARA EL SIGLO XX1 Iniciativa para el liderazgo y la calidad de la democracia en América Latina LIDERA.

- Movimientos sociales frente a la impunidad en Centroamérica y México. Revista de la Fundación Rosa Luxemburgo México.

\section{Zulma Larín de Vides}

Graduada de la Licenciatura en Ciencias de la Educación, en el año 1998, posteriormente desarrollo estudios de Maestría En Gestión Ambiental en la Universidad Nacional de El Salvador UES, (2008) Así como he cursado Diplomados en Genero/Desarrollo y Elaboración de Planteamiento estratégicos; Así mismo en su desarrollo profesional, ha trabajado como Facilitadora de Coordinación Nacional en la Pastoral Juvenil de la Iglesia Luterana Salvadoreña 1,992 al 1,997, Administradora General de Los Colegios Luteranos Salvadoreños 1998 al 2000 trabajó como Docente de la carrera en Ciencias de la educación en la Universidad Luterana Salvadoreña en los años 1999 al 2002, como Supervisora de Practicas Docentes; Catedrática de materias en la Universidad Panamericana y la Universidad Nacional de El Salvador. Técnica para la promoción de los Derechos Económicos Sociales y Culturales. FESPAD, Técnica para la promoción y sensibilización ambiental en UNES; Activista y defensora de Derechos Humanos; Ambientalista en las apuestas y defensa de que otra relación es posible con los otros seres vivientes del planeta. Fundadora de RACDES; Organización ambientalista que desarrolla trabajo de educación ambiental a nivel comunitario y acompaña toda acción de incidencia que proteja la vida animal, vegetal y humana. Actualmente directora de la Asociación Popol-na/RACDES. 